\title{
Infrared imaging investigation of temperature fluctuation and spatial distribution for a large laminated lithium-ion power battery
}

\author{
Shixue Wang ${ }^{1}$, Kaixiang $\mathrm{Li}^{1}$, Yuan Tian ${ }^{2,}{ }^{*}$, Junyao Wang${ }^{1}$, Yukang $\mathrm{Wu}^{1}$, Shan $\mathrm{Ji}^{1}$ \\ ${ }^{1}$ Key Laboratory of Efficient Utilization of Low and Medium Grade Energy (Tianjin University), \\ Ministry of Education, Tianjin 300072, China \\ ${ }^{2}$ Institute of Energy and Sustainable Development, School of Engineering and Sustainable \\ Development, De Montfort University, Leicester LE1 9BH, UK
}

\begin{abstract}
The present study investigates the thermal behaviors of a naturally cooled NCMtype LIB ( $\mathrm{LiNi}_{1-\mathrm{x}-\mathrm{y}} \mathrm{Co}_{\mathrm{x}} \mathrm{Mn}_{\mathrm{y}} \mathrm{O}_{2}$ as cathode) from an experimental and systematic approach. The temperature distribution was acquired for different discharge rates and Depth of Discharge (DOD) by the infrared imaging (IR) technology. Two new factors, the temperature variance $\left(T_{\mathrm{var}}^{2}\right)$ and local overheating index ( $\mathrm{LOH}$ index), were proposed to assess the temperature fluctuation and distribution. Results showed that the heat generation rate was higher on the cathode side than that on the anode side due to the different resistivity of current collectors. For a low-power discharge, the eventual stable high-temperature zone occurred in the center of the battery, while with a high-power discharge, the upper part of the battery was the high-temperature region from the very beginning of discharge. It was found that the temperature variance ( $T_{\mathrm{var}}^{2}$ ) and local overheating index ( $\mathrm{LOH}$ index) were capable of holistically exhibiting the temperature non-uniformity both on numerical fluctuation and spatial distribution with varying discharge rates and DOD. With increasing the discharge rate and DOD, temperature distribution showed an increasingly non-uniform trend, especially at the initial and final stage of high-power discharge, the heat accumulation and concentration area increased rapidly.
\end{abstract}

Keywords: Large-size lithium-ion battery; local overheating; temperature spatial distribution; infrared temperature measurement.

Full article available at Elsevier:

S. Wang, K. Li, Y. Tian, J. Wang, Y. Wu, S. Ji, “Infrared Imaging Investigation of Temperature Fluctuation and Spatial Distribution for a Large Laminated Lithium-ion Power Battery”, Applied Thermal Engineering, 152, 2019, pp. 204-214, https://doi.org/10.1016/j.applthermaleng.2019.02.096 


Nomenclature
\begin{tabular}{|ll|}
\hline$A$ & Tab distance (mm) \\
$B 1$ & Cathode tab width (mm) \\
$B 2$ & Anode tab width $(\mathrm{mm})$ \\
$C$ & Anode tab apothem (mm) \\
$D$ & Height of sealant $(\mathrm{mm})$ \\
$h$ & Height of battery (mm) \\
$h 1$ & Height of tabs $(\mathrm{mm})$ \\
$h 2$ & Top side height $(\mathrm{mm})$ \\
$h 3$ & Bottom side height $(\mathrm{mm})$ \\
$T$ & Thickness of battery $(\mathrm{mm})$ \\
$T_{h}$ & The highest temperature $\left({ }^{\circ} \mathrm{C}\right)$ \\
$T_{i}$ & The initial temperature $\left({ }^{\circ} \mathrm{C}\right)$ \\
$T_{i n c}$ & The maximum temperature increase $\left({ }^{\circ} \mathrm{C}\right)$ \\
$T_{l}$ & The lowest temperature $\left({ }^{\circ} \mathrm{C}\right)$ \\
$\Delta T_{\max }$ & The maximum temperature difference $\left({ }^{\circ} \mathrm{C}\right)$ \\
$T_{\max }$ & The highest temperature point in IR image $\left({ }^{\circ} \mathrm{C}\right)$ \\
$T_{\text {var }}^{2}$ & The temperature variance $\left({ }^{\circ} \mathrm{C}\right)$ \\
$W$ & Width of battery (mm) \\
$W 1$ & Side width (mm) \\
\hline
\end{tabular}

\section{Introduction}

Lithium-ion batteries (LIBs) have great potential for Electric Vehicles (EV) [1]. Nevertheless, large temperature variation and heat concentration during the charge and discharge processes are still critical challenges for the laminated LIBs [2, 3]. In fact, the thermal issues of large lithium-ion power batteries have always been a bottleneck which restricts the development of the EV. In addition, the thermal safety of LIBs is becoming increasingly critical, as it gets much more difficult to curb the thermal runaway of large power LIBs caused by the local overheating compared to ordinary batteries. Thermal runaway is highly hazardous with every effort made to prevent it from happening.

In order to solve the thermal-related issues of LIBs and improve thermal safety performance, a mountain of studies have been conducted to explore the thermal behaviors. Zhang et al. [4] investigated the temperature spatial distribution and thermal generation properties of LIBs and proposed an optimized thermal design by an analytic solution. Giuliano et al. [5] experimentally investigated the Lithium Titanium Oxide (LTO) batteries for its thermal properties and proposed a novel cooling system for LTO according to its heat production characteristics. Onda et al. [6] studied thermal behaviors of small-sized lithium-ion batteries during fast charging and discharging cycles, during which the cell temperature might increase over the allowable limits. Wang et al. [7] investigated the thermal behaviors of the NCM Li- 
ion battery in the condition that the battery was overcharged. In their experiments, the batteries were overcharged to $4.6 \sim 5.0 \mathrm{~V}$. Their results showed that the battery thermal behavior of the cathode was mainly affected by the electrolyte reaction, in which the evolutional oxygen was predominant in the thermal dissipation of the LIB under the specific experimental conditions. Zhao et al. [8] studied the thermal behaviors of LIBs with an addition of a typical heat source by an experimental approach. It was found that the reversible heat had a significant influence on the temperature variation of the battery. An optimized electrochemical-thermal numerical model was proposed to incorporate the reversible heat. In addition, Xiao et al. [9] measured different heat generation components of a pouch LIB and validated their electrochemical-thermal model by measurement results.

The electrochemical-thermal numerical simulation based on the thermal equilibrium model is an ideal approach to reveal the mechanism underlying the temperature distribution, to evaluate the thermal safety of battery and to refine the thermal design. Kim et al. [10] reported a modeling approach for their scaled-up lithium-ion polymer battery (LIPB), where the temperature distributions of the LIPB were calculated based on the modeling results. Chacko et al. [11] implemented a three-dimensional transient electro-thermal model based on a finite volume method. The cell-level thermal behavior under stressful conditions was predicted with the model. Inui et al. [12] developed 2D and 3D simulation models of the transient response of the temperature distribution in the lithium ion battery during discharge cycles. Huria et al. [13] presented an effective method for developing a multi-temperature lithium cell simulation model with thermal dependence. Yi et al. [14] reported the combined effects of the thermal and electrical contact resistances between the current collecting tab of LIB cell and the lead wire. Previous studies to improve the accuracy of numerical models mainly focused on the multi-physical (electrochemical-thermal) models Zhao et al. [15] developed a threedimensional model of a stagger-arranged battery pack and investigated the effects of the cooling channel size and air supply strategy on the thermal behavior. Guo et al. [16] designed a distributed thermal model for a lithium-ion electrode plate pair used to predict the distributed electrical and thermal behavior of the electrode pair including tabs. Lee et al. [17] developed the wound potential-pair continuum (WPPC) model as a cell domain sub model to solve heat and electron transfer across the length scale of the cell dimension. Mao et al. [18] used the Dualfoil model to simulate the electrochemical behavior and temperature rise for $\mathrm{MCMB} / \mathrm{LiCoO}_{2} \mathrm{Li}$-ion cells under a small constant-resistance load, approaching a shortcircuit condition. Sun et al. [19] investigated the performance and thermal response of largescale automotive battery cells via simulations to evaluate local transient temperature distributions. These multi-physical models were used to study the distribution and the evolution of the temperature, ion concentration, current density and potential under different 
experimental conditions. Bin et al. [20] and $\mathrm{Li}$ et al. [21] established different heat effect models, which indicated that under high-temperature conditions, the cycle capacity and the lifespan of LIBs would be significantly deteriorated. Kim et al. [22] developed a thermal modeling to study the effect of the electrode configuration on the thermal behaviors of a lithium-polymer battery. The results indicated that the current collecting tabs have a significant impact on the thermal behaviors of the battery. Dong [23] developed a numerical modeling for predicting the thermal behaviors of the lithium-ion battery. It was indicated that the increase in the temperature rising during the discharging process is higher than that during the charging process. In addition, it was found that the thermal behaviors were closely affected by the entropy change. Niculuţa et al. [24] conducted theoretical experimental and numerical studies to investigate the electrothermal characteristics of the Lithium Iron Phosphate (LiFePO) battery cells. Results revealed that the central cells in the pack have the biggest risk of overheating due to the maximum temperature and the lowest thermal dissipation rate in the central area.

Existing studies are facing challenges. (1) The temperature distribution is not negligible for a large cell. Despite that the temperature distribution is negligible for a single small cell, the situation is completely different in a cell of large size or many small cells in a large battery pack, where the rather large temperature difference within a cell or a pack cannot be neglected. In the deployment of large laminated lithium-ion batteries, thermal issues become critical due to the larger cell size and the scaled-up heat production [25, 26], thus making temperature difference within the cell non-negligible. The temperature non-uniformity of a cell is usually neglected in most traditional cooling systems, but it has a significant influence on a large cell. Solving thermal issues is not just about dissipating the generated heat at the required rate, beyond which the heat generation and distribution in space and time should also be taken into account. To better understand and optimize the thermal management of battery packs, the internal thermal behaviors of a single battery cell need to be investigated as a starting point, which was rarely considered but often neglected in previous studies due to the small size of the cells.

(2) The numerical modeling for predicting the temperature distribution in a large cell is not accurate. A cell consists of multiple layers of active material, separators and electrodes. Resolving heat transfer equations for all these thin layers is not only computationally expensive but also physically unnecessary if the interest is to get an overall temperature distribution across the battery. The cell with layered structures causes anisotropic thermal conductivities in the directions parallel and perpendicular to the layers. Most published studies based their thermal models on uniform heat production, including the 
widely used Newman model. Such assumptions made computation less troublesome; however, the results often lacked accuracy especially under the condition of high discharge rates. Experimental temperature measurement is the best and most reliable approach to solve such problems, providing accurate data of real temperature distribution and meanwhile serving as a benchmark to testing the precision of a battery thermal model.

(3) Traditional temperature evaluation method fail to reveal overall thermal characteristics of large cells. Most existing thermometry methods were based on point measurement using the maximum temperature rise and temperature difference as main assessment indicators. Very often, such point measurements have low resolution because it is just not possible to place as many thermocouples as possible onto a battery cell, and worse still, doing so would affect temperatures inevitably. The IR technology with a much higher resolution, however, makes contactless measurements possible, thus the temperature conditions of a battery can be assessed accurately and holistically. In the current study, IR was adopted to investigate the thermal characteristics of laminated LIBs in different discharge rates and discharge depth under the condition of natural convection. Previous research has shown that thermal runaway of batteries was always caused by localized overheating [27, 28], and therefore for the thermal safety, it is very important to assess the temperature fluctuation and the local overheating of battery accurately. However, this is a situation which cannot be described and analyzed based on traditional thermal evaluation indexes. Compared to previous studies, the novelty and contributions of the current study are: the temperature variance $\left(T_{\mathrm{var}}^{2}\right)$ and the local overheating index ( $\mathrm{LOH}$ index) were proposed, for the first time, to quantitatively assess the temperature distribution and variation for battery cells. $T_{\text {var }}^{2}$ was used to assess numerical deviation of temperatures while the local overheating index (LOH index) was used to evaluate the spatial distribution of high-temperature points. The experimental results and relevant analyses quantified the heat generation and distribution in space and time, revealed different thermal characteristics between high and low power discharge rates and provided a certain reference for the battery thermal management design. All these factors can be used in predicting heat accumulation and preventing thermal runaway.

\section{Experimental settings}

\subsection{Experimental system}

Fig. 1 (a) shows the experimental system of the thermal behaviors of a laminated LIB. The charge and discharge cycles were regulated by the battery charge/discharge system (max input power $23 \mathrm{~kW}$ ) controlled by the programmable software. The voltage, current and resistant data can be collected in the experimental system. In the current study, the industrial 
IR imager measures the battery thermal performance in the charge/discharge processes, while the T-type thermocouples calibrate the temperature measurement from IR. The measured temperature difference between the infrared imager and the thermocouples has a maximum tolerance of $0.1^{\circ} \mathrm{C}$ allowed. It was noted that the ambient light contains infrared ray and may form a reflection on the batteries surface to affect the measurement error of the infrared imager. Therefore, to eliminate such effects, a light shade was applied to block the infrared ray of the ambient light, as shown in Fig. 1 (a). As a result, the maximum measurement error by the infrared imager was less than $0.1^{\circ} \mathrm{C}$. The IR imager was fixed on a camera tripod and perpendicular to the measured surface. The distance from the surface of the battery cell to the lens was 0.6 meters.

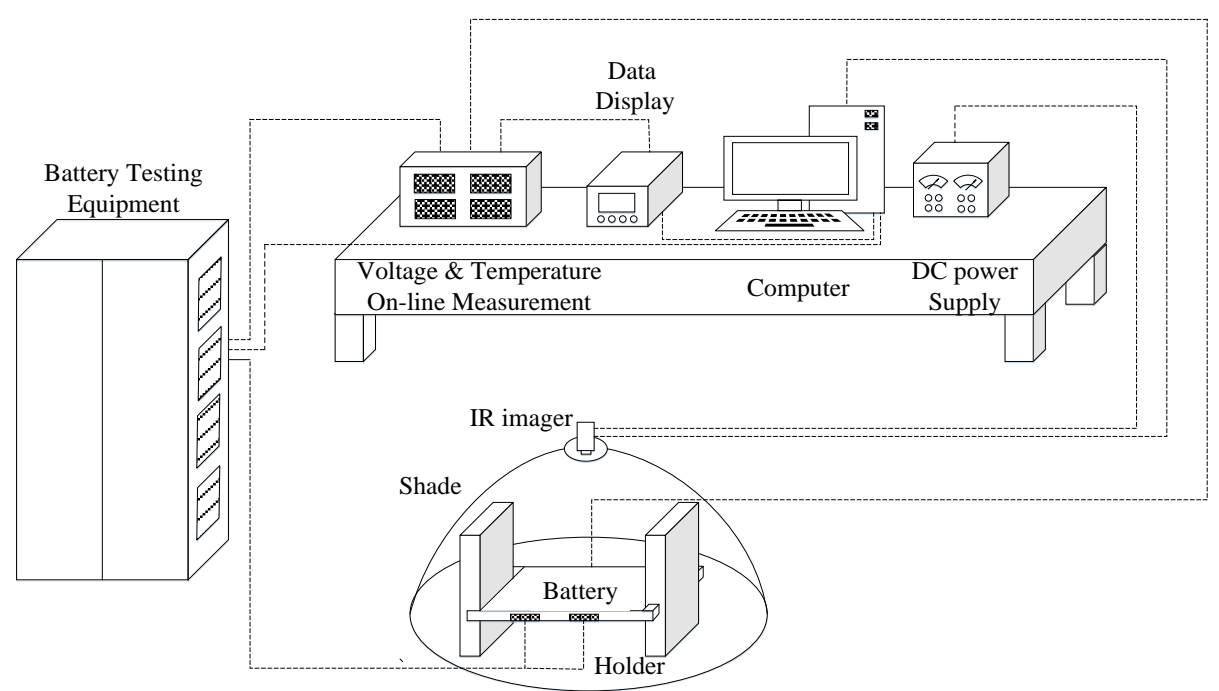

(a) Experiment schematic

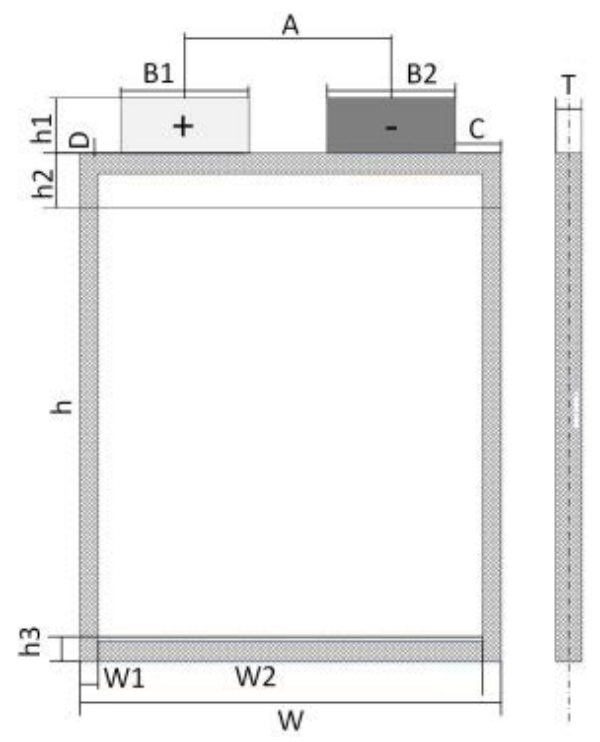

(b) Cell dimension

Fig. 1. Experimental setup 
The pouch Cell $(T 7.1 \mathrm{~mm} \times H 268 \mathrm{~mm} \times W 211 \mathrm{~mm})$ has a nominal capacity of $37000 \mathrm{mAh}$ and a nominal voltage of $3.65 \mathrm{~V}$, as shown in Fig. 1 (b) and Table 1. The negative current collecting tabs are made of copper in dark color while the positive current collecting tabs are made of aluminum in light color. Adiabatic plastic clamps were applied to the cell and fixed at the edge parts to ensure that the battery was only exposed to air and not touched by any other experimental components.

Table 1. Cell dimension

\begin{tabular}{cccc}
\hline objects & value (mm) & objects & value (mm) \\
\hline With of battery $(W)$ & 211 & Side width $(W 1)$ & 8 \\
Height of battery $(h)$ & 268 & Thickness of battery $(T)$ & 7.1 \\
Tab distance $(A)$ & 100 & Cathode tab width $(B 1)$ & 60 \\
Anode tab width $(B 2)$ & 60 & Anode tab apothem $(C)$ & 25.5 \\
Height of sealant $(D)$ & 2.0 & Height of tabs $(h 1)$ & 19 \\
Top side height $(h 2)$ & 19 & Bottom side height $(h 3)$ & 8 \\
\hline
\end{tabular}

\subsection{Experimental procedures}

This experiment aims to explore the thermal behavior of the laminated LIB in the condition of natural convection. Therefore, during the experimental process no wind was allowed. The ambient temperature was maintained at $25 \pm 1^{\circ} \mathrm{C}$ with the maximum variation of $2^{\circ} \mathrm{C}$. A central thermostatic air-conditioning was used to maintain the ambient temperature. The battery temperature was measured under different charge/discharge rates of $0.5 \mathrm{C}-3 \mathrm{C}$ with a cut-off voltage of $2.80 \mathrm{~V}$. The standard CC-CV method was applied to battery charge process, in which a battery was initially charged at a constant current of $0.5 \mathrm{C}$ until the voltage reaches $4.20 \mathrm{~V}$, and then charged at a constant voltage mode. When the charging current drops to less than $0.05 \mathrm{C}$ then charging process was ended. At this time, the discharge process begins so as to dissipate the thermal energy to the atmosphere by means of natural convection and thermal radiation. The parameters of the infrared imager are shown in Table 2, was well calibrated and applied to measure the battery temperature in both charging and discharging processes. As the thickness of the laminated cell $(7.1 \mathrm{~mm})$ is rather thin, the maximum temperature difference within the battery cell is safely neglected. As a consequence, only the surface temperature of the battery cell was measured by thermocouples in the experiments. However, the temperature distribution can be acquired by the infrared imager with a high accuracy and resolution since there was no physical contact and the influence of the ambient was eliminated by the shield in the experiment. 
In the current study, the infrared imager was adapted to measure the battery surface temperature, with T-type thermocouples used as calibration. Measurement errors include: 1) degree of accuracy, where T-type thermocouples were calibrated by an ice water mixture in a vacuum bottle to ensure the difference between the measured and the real temperature was below $0.1^{\circ} \mathrm{C} ; 2$ ) degree of precision, where the measured temperature difference between the infrared imager and thermocouples was allowed to be no more than $0.1{ }^{\circ} \mathrm{C}$ during the experiments by adjusting the battery surface emissivity; 3) repeatability, where the surface temperature of the battery was measured several times at room temperature $\left(25^{\circ} \mathrm{C}\right)$ with an error less than $0.1^{\circ} \mathrm{C}$; 4) reproducibility, where the surface temperature of the battery was measured several times at $50{ }^{\circ} \mathrm{C}$ in the high-temperature test chamber, with the measured temperature difference between the infrared imager and the thermocouples below $0.1^{\circ} \mathrm{C}$.

Table 2. IR imager settings.

\begin{tabular}{cccc}
\hline Items & Parameter & Items & Parameter \\
\hline $\begin{array}{c}\text { Environmental } \\
\text { temperature }\end{array}$ & $25^{\circ} \mathrm{C}$ & Thermal infrared emissivity & 0.60 \\
$\begin{array}{c}\text { Environmental } \\
\text { humidity }\end{array}$ & $55 \%$ & Photographic distance & $0.60 \mathrm{~m}$ \\
\hline
\end{tabular}

\subsection{Key parameters}

The maximum temperature increase ( $T_{i n c}$ ) represents the temperature difference between the highest temperature $\left(T_{h}\right)$ and the initial temperature $\left(T_{i}\right)$ of the battery cell, which is defined and calculated by Eq. (1):

$$
T_{i n c}=T_{h}-T_{i}
$$

The maximum temperature difference ( $\Delta T_{\max }$ ) denotes the temperature difference between $T_{h}$ and the lowest temperature ( $\left.T_{l}\right)$, as shown in Eq. (2),

$$
\Delta T_{\max }=T_{h}-T_{l}
$$

The temperature variance $\left(T_{\mathrm{var}}^{2}\right)$ is defined to show the temperature uniformity of the battery cell. As the temperature distribution of the battery cell can be obtained from the infrared imager, the temperature variance $\left(T_{\mathrm{var}}^{2}\right)$ can be estimated by accounting the frequency of temperature occurrence in each pixel dot. The specific expression of the temperature variance is described as:

$$
T_{\mathrm{var}}^{2}=\sum_{i}^{n} f_{i}\left(x_{i}-\bar{x}\right)^{2}
$$


where $f_{i}$ denotes the frequency of a $0.1^{\circ} \mathrm{C}$ temperature range, and $\bar{x}$ denotes the average of total temperature data.

\subsection{Local overheating programming}

The maximum temperature difference and maximum temperature rise cannot accurately describe the overall temperature of the battery. Therefore, MATLAB programming was used for temperature data analysis, with its operation procedure shown in Fig. 2. Firstly, the temperature data (with coordinate information) of the top $10 \%$ of the high-temperature points were selected and matrixed, then the average distance (dimensionless) of all high-temperature points to the maximum temperature point was calculated. The convergent and divergent extent of high-temperature data can be characterized by the average distance, indicating the battery local overheating trend and the risk of thermal runaway. As shown in Fig. 2, decentralized high-temperature points indicate a larger $\mathrm{LOH}$ index, while centralized ones indicate smaller $\mathrm{LOH}$.

In the calculation of LOH Index, the random error caused by randomly selecting of $T_{\max }$ was limited (less than $0.01 \%$ ). In addition, the selection of independent variable should not have an effect on output results. To prove the $\mathrm{LOH}$ algorithm is reliable, a sensitivity analysis of independent variables was calculated, with $5 \%, 10 \%$ and $15 \%$ samples chosen from the overall data as independent variables, respectively. Test results showed that the trend of the dependent variables corresponding to the output was almost identical, which proves that the algorithm is reliable and robust, and that it was wise to choose just $10 \%$ of the hightemperature samples. 


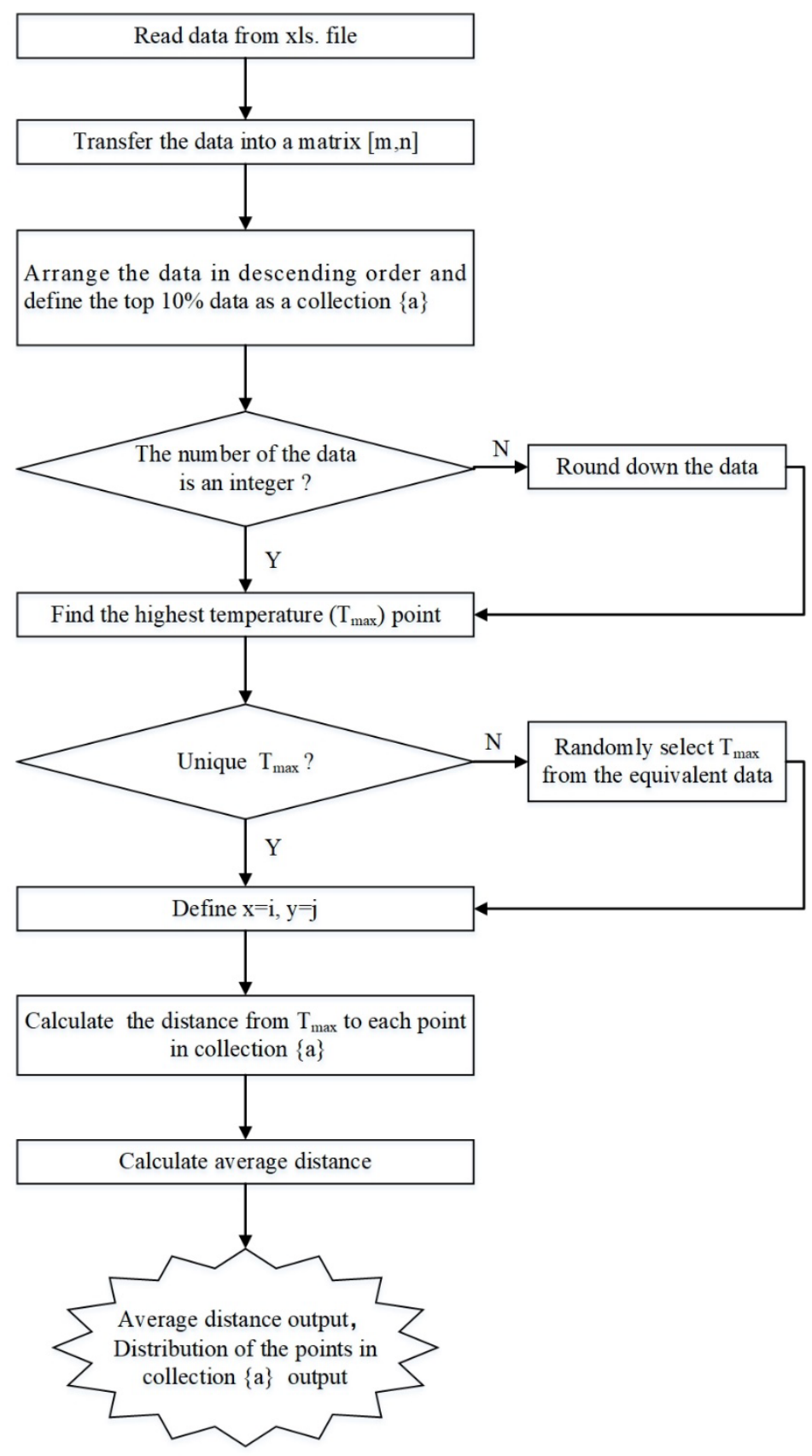

Fig. 2. The operation logic of LOH Index

\section{Results and discussions}

\subsection{Temperature distribution}

The experiment result shows that heat generation rates were heterogeneously distributed in different parts of the battery cell during the discharge process. Therefore, the design of a thermal management system for the battery should be treated differently in the lowtemperature and high-temperature zones. In addition, the experiment results showed that the temperature distribution and variation trend between high discharge rates and low discharge rates were entirely different. 
As shown in Fig. 3, a frame of rectangular coordinate was set up for the cell, where the $T_{h}$ and $T_{l}$ points can be located with coordinates accurately. Under a constant discharge rate of 3C the coordinates of $T_{h}$ and $T_{l}$ points location shown in Table 3. $T_{h}$ and $T_{l}$ tend to be relatively fixed after around $100 \mathrm{~s}$ and the $T_{h}$ and $T_{l}$ region can be identified. $T_{h}$ area can be concluded as $\{(x, y) \mid x \in-55.6 \sim-37.8, y \in 106.2 \sim 120.4\}$ and $T_{l}$ was $\{(x, y) \mid x \in 45.9 \sim 97.5, y \in-$ $102.3 \sim-117.5\}$.

As Fig. 3 demonstrated, the temperature distribution along the center lines of the positive tab $(x=-50)$ and the negative tab $(x=50)$ at $600 \mathrm{~s}$ were defined as Line 1 and Line 2, respectively. Line $3(y=113.3)$, and Line $5(y=-110.6)$ pass through central points of $T_{h}$ and $T_{l}$, respectively. Line $4(y=0)$ passes through the dead center of the battery.

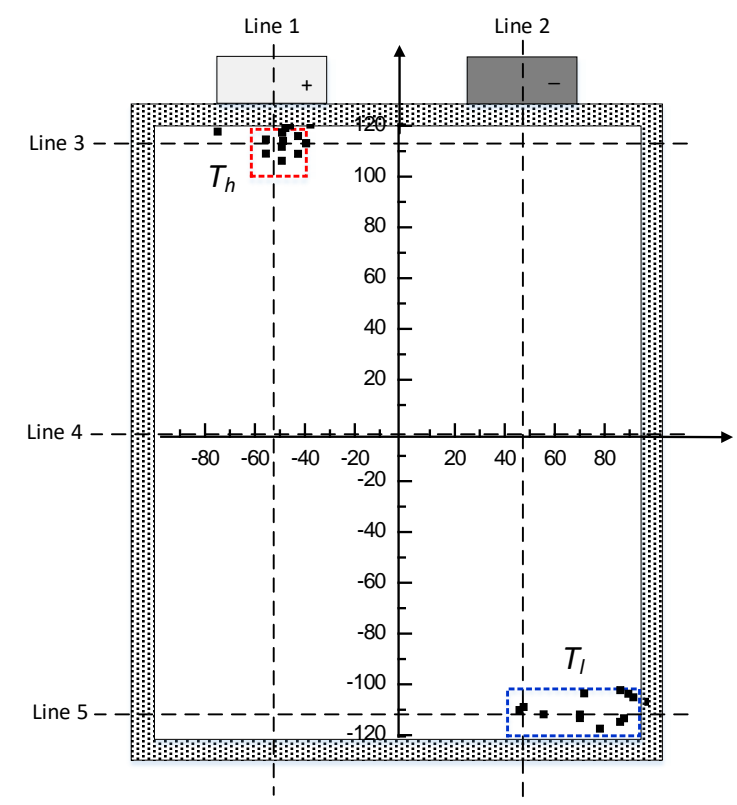

Fig. 3. Coordinates of $T_{h}$ and $T_{l}$

Table 3. The Location of $T_{h}$ and $T_{l}$ point

\begin{tabular}{cccccccc}
\hline $\begin{array}{c}\text { Time } \\
(\mathbf{s})\end{array}$ & $\begin{array}{c}\text { Coordinate of } \\
T_{h}\end{array}$ & $\begin{array}{c}\text { Coordinate of } \\
T_{l}\end{array}$ & $\begin{array}{c}\text { Max Temp. } \\
\text { difference } \\
\left({ }^{\circ} \mathbf{C}\right)\end{array}$ & $\begin{array}{c}\text { Time } \\
(\mathbf{s})\end{array}$ & $\begin{array}{c}\text { Coordinate of } \\
T_{h}\end{array}$ & $\begin{array}{c}\text { Coordinate of } \\
T_{l}\end{array}$ & $\begin{array}{c}\text { Max. Temp. } \\
\text { difference } \\
\left({ }^{\circ} \mathbf{C}\right)\end{array}$ \\
\hline 100 & $(-74.9$, & $(97.5$, & 4.7 & 700 & $(-49.2$, & $(71.8$, & 8.9 \\
& $117.7)$ & $-106.9)$ & & & $111.7)$ & $-103.6)$ & \\
200 & $(-48.7$, & $(91.5$, & 7.7 & 800 & $(-55.6$, & $(78.1$, & 7.6 \\
& $114.0)$ & $-105.1)$ & & & $114.6)$ & $-117.5)$ & \\
\hline
\end{tabular}




\begin{tabular}{llcccccc}
\hline 300 & $(-37.8$, & $(86.2$, & 11.9 & 900 & $(-55.6$, & $(87.8$, & 9.6 \\
& $120.4)$ & $-114.8)$ & & & $109.0)$ & $-113.4)$ & \\
400 & $(-42.7$, & $(89.5$, & 12.2 & 100 & $(-42.7$, & $(70.1$, & 9.4 \\
& $115.9)$ & $-103.7)$ & & 0 & $108.9)$ & $-111.9)$ & \\
\multirow{2}{*}{500} & $(-49.1$, & $(70.1$, & 10.9 & 110 & $(-49.2$, & $(55.6$, & 9.3 \\
& $117.3)$ & $-113.3)$ & & 0 & $106.2)$ & $-111.8)$ & \\
600 & $(-39.5$, & $(86.3$, & 11.5 & 120 & $(-45.9$, & $(47.6$, & 9 \\
& $113.1)$ & $-102.3)$ & & 0 & $120.1)$ & $-108.9)$ & \\
\hline
\end{tabular}

Fig. 4 shows the line analysis for battery temperature distribution. Specifically, Fig. 4 (a) indicated the battery temperature fluctuation along Line 1 and Line 2 . It was evident that the temperature on the negative electrode side was lower than that on the positive electrode side, as the copper has lower electrical resistivity than that of aluminum. The ohmic heat generation rate of the positive current collector was $80 \%$ more than that of the negative current collector theoretically. Fig. 4 (b) presents the temperature distribution along Line 3, Line 4 and Line 5, respectively. It was seen that Line 3 which part is near the current collectors has the highest temperature compared with Line 4 and Line 5 . The temperature in Line 3 has the largest fluctuations with two symmetric peaks at its two electrodes, because the main heat source was at the two electrodes. The temperatures were more uniform in central and bottom areas (i.e. Line 4 and Line 5). The temperature difference between positive and negative tabs was mainly due to the difference in materials: $0.0283 \Omega \mathrm{mm}^{2} / \mathrm{m}$ and 0.01851 $\Omega \mathrm{mm}^{2} / \mathrm{m}$ (resistivity) for aluminum and copper, respectively. With collectors of the same size and equal current density, the ratio of the irreversible heat producing rate is 1.8 (positive): 1 (negative), thus the irreversible heat flux form positive tab to batteries is always higher than the negative.

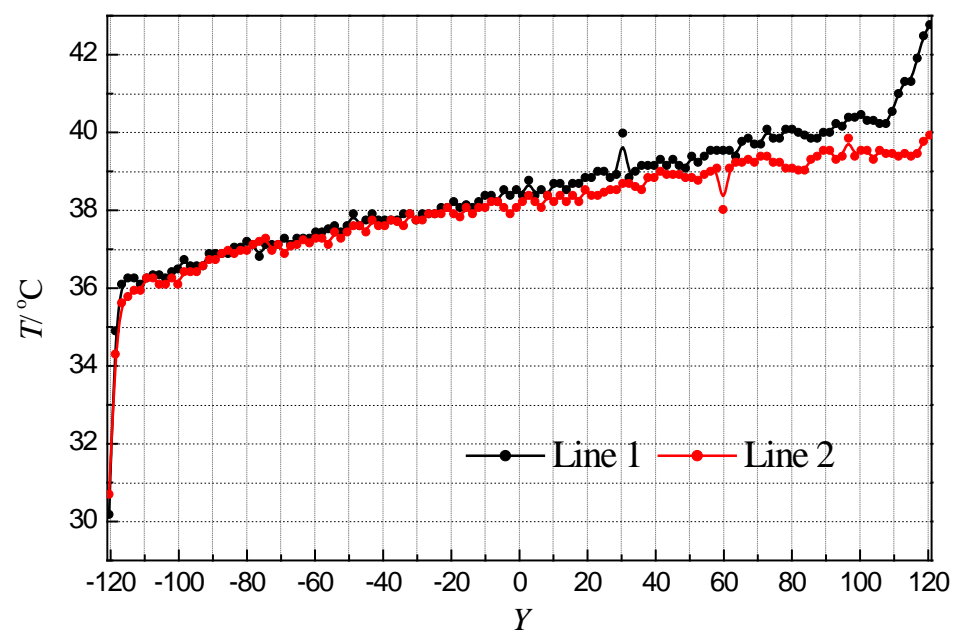

(a) $3 \mathrm{C}$ at $50 \% \mathrm{DOD}$ 


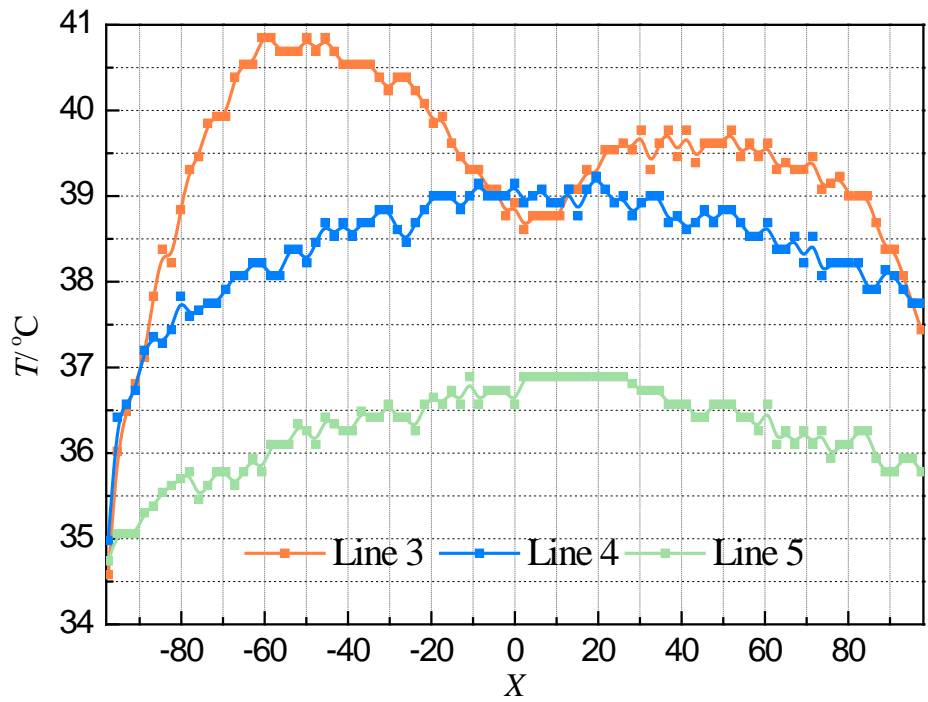

(b) $3 \mathrm{C}$ at $50 \% \mathrm{DOD}$

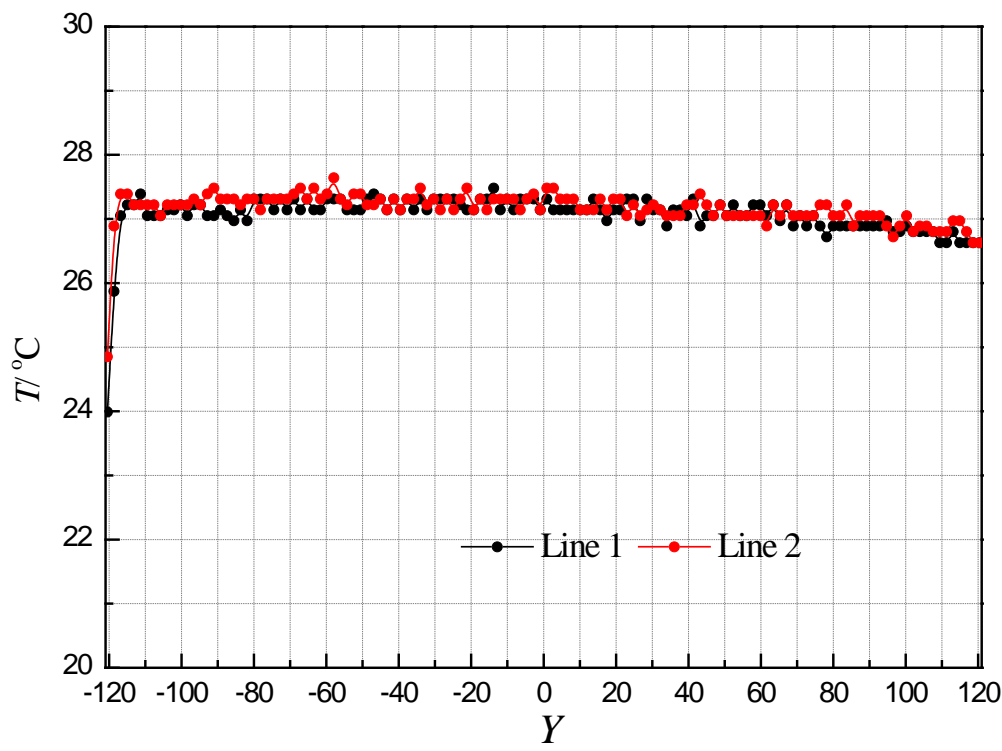

(c) $0.5 \mathrm{C}$ at $50 \% \mathrm{DOD}$ 


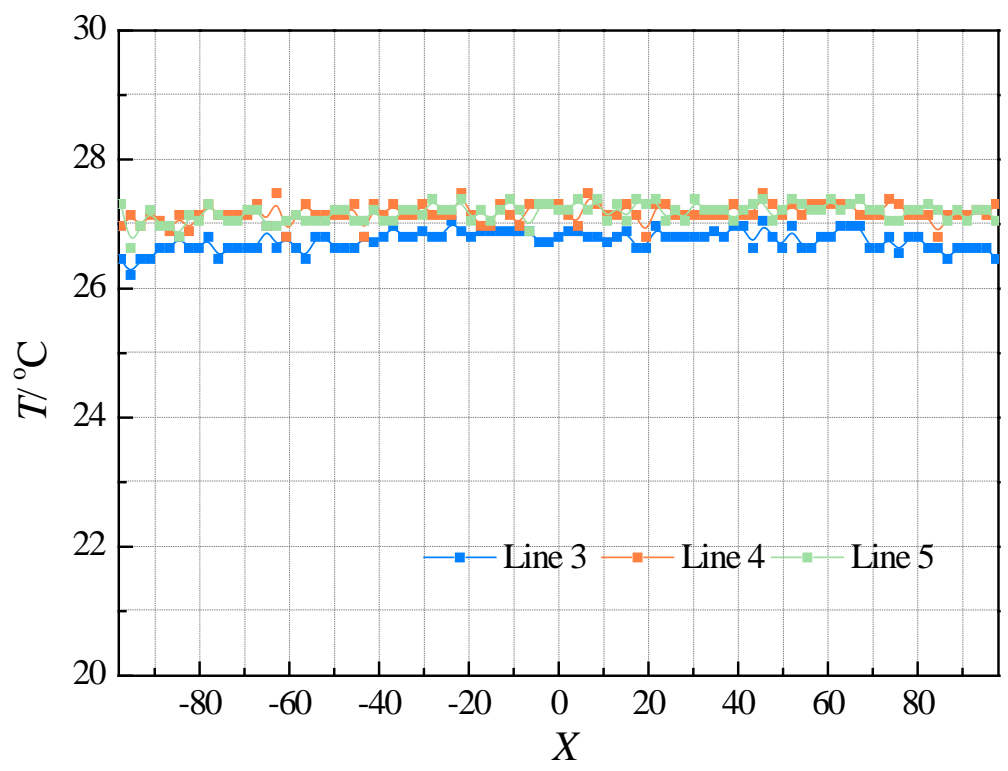

(d) $0.5 \mathrm{C}$ at $50 \% \mathrm{DOD}$

Fig. 4. Line analysis of battery temperature distribution at $0.5 \mathrm{C}$ and $3 \mathrm{C}$

As shown in Fig. 4 (c) (d), there was a significant difference in temperature distribution between low-power discharging and high-power discharging. Under the condition of constant discharge rate at $0.5 \mathrm{C}$, the ohmic heat decreases exponentially due to the current density drop, temperature difference caused by the resistivity of the positive and negative tab was no longer apparent. Line 1 and Line 2 were highly coincident, and the temperature on both sides of the positive and negative tab of the battery was relatively uniform. There was no heat aggregation under the positive and negative tab. In the $Y$ direction, the temperature distribution was contrary to the high-power discharging, the high-temperature area in the middle stage of lowpower discharging was located in the middle of the battery. Meanwhile, the temperature at the upper area was lower (Line 3). To make a comparison between Fig. 4 (a), (b) and Fig. 4 (c), (d), line analysis shows that the overall temperature gradient on the battery surface was small and the temperature distribution is uniform under the condition of low power discharging. In this case, reversible heat is dominant with heat source uniformly distributed, while the thermal resistance was not uniformly distributed due to its current collection arrangement. Current collector has much lower temperatures than battery, and consequently heat was transferred from battery to current collector (the opposite direction in high-power discharging).

The temperature distribution at low discharge rates was different from that at high rates. Fig. 5 shows the changes of the temperature distribution with different DOD $(10 \%, 30 \%, 50 \%$, 70\% and 90\%) under 0.5 C, 1 C, 2.5 C and 3 C, respectively. In order to clearly distinguish 
the contour of the high-temperature region, the IR color display was adjusted to the discontinuous change.

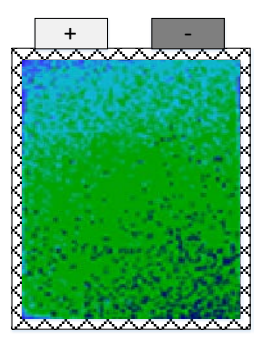

(1) $10 \% \mathrm{DOD}$

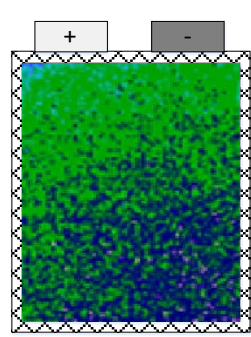

(2) $30 \%$ DOD

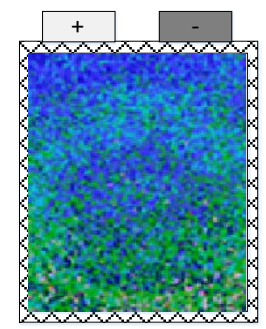

(3) $50 \%$ DOD

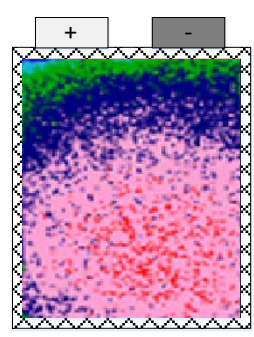

(4) $70 \% \mathrm{DOD}$

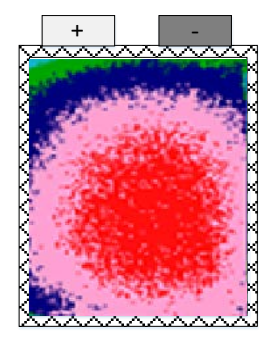

(5) $90 \% \mathrm{DOD}$

(a) Temperature distribution at $0.5 \mathrm{C}$

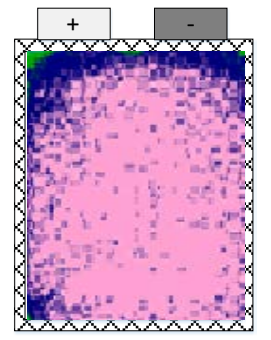

(1) $10 \%$ DOD

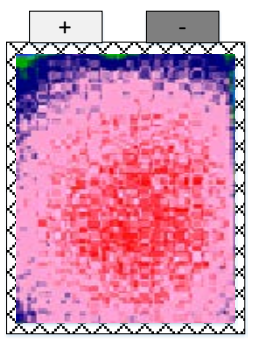

(2) $30 \%$ DOD

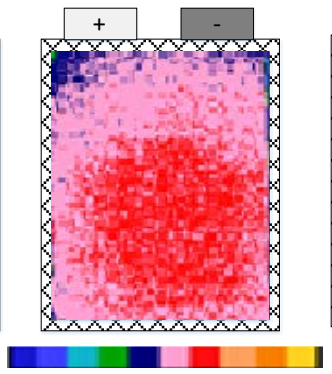

(3) $50 \%$ DOD

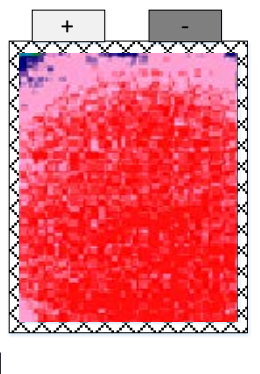

(4) $70 \% \mathrm{DOD}$

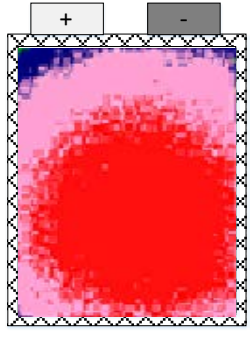

(5) $90 \% \mathrm{DOD}$

(b) Temperature distribution at $1 \mathrm{C}$

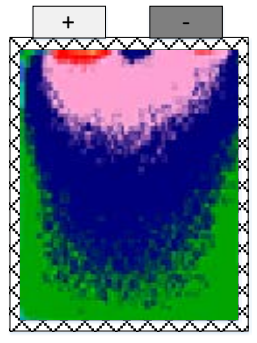

(1) $10 \% \mathrm{DOD}$

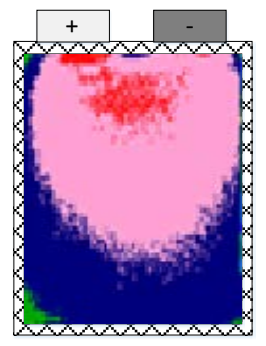

(2) $30 \%$ DOD
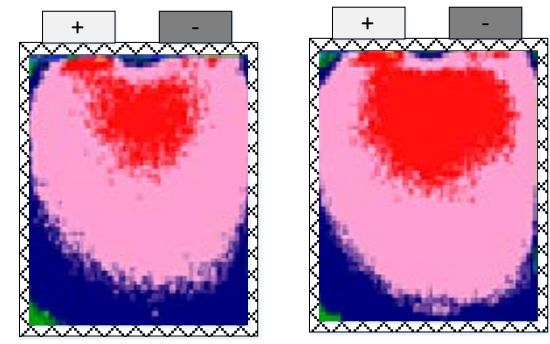

(3) $50 \% \mathrm{DOD}$

(4) $70 \% \mathrm{DOD}$

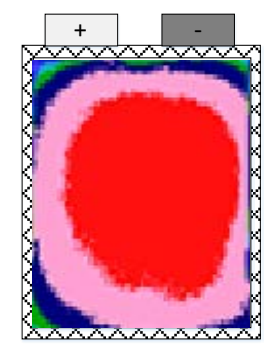

(c) Temperature distribution at $2.5 \mathrm{C}$
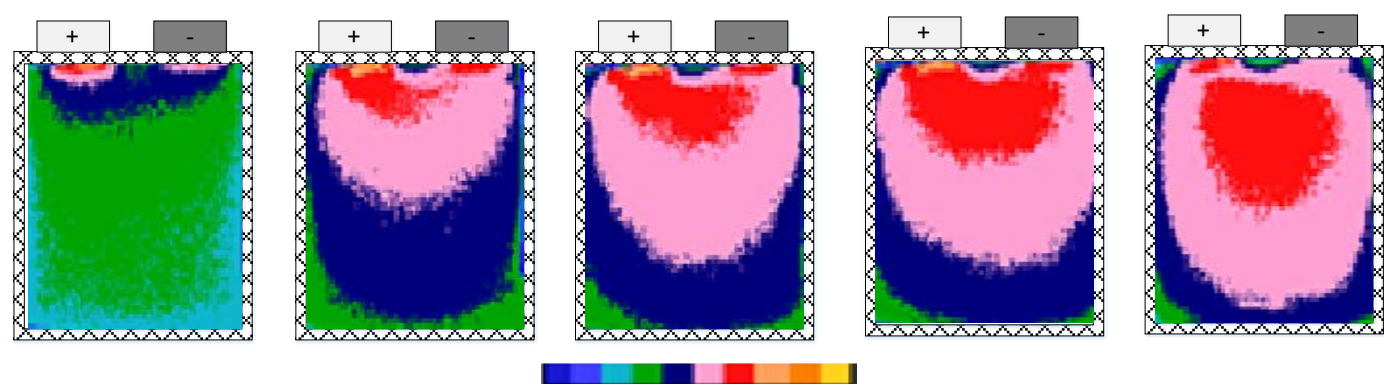

(1) $10 \% \mathrm{DOD}$

(2) $30 \% \mathrm{DOD}$

(3) $50 \%$ DOD

(4) $70 \% \mathrm{DOD}$

(5) $90 \% \mathrm{DOD}$ 
(d) Temperature distribution at $3 \mathrm{C}$

Fig. 5. IR Temperature distribution at $0.5 \mathrm{C}, 1 \mathrm{C}, 2.5 \mathrm{C}$ and $3 \mathrm{C}$.

The experiments were conducted in the approved output power and temperature range with the coulomb efficiency close to 1 , and hence the side reaction heat of battery can be neglected. There were mainly two parts of the internal irreversible heat generation: one arises from ohmic heat generation and the other one from the polarization. According to the infrared images above, in the condition of a low discharge rate, the battery temperature distribution was relatively uniform, and the final high-temperature zone was formed and stable in the centre of the battery after 70\% DOD, while the low-temperature zone appears in the upper area, because the reaction heat holds a large proportion and the output current was small in this case. However, with a high discharge rate, the upper part of the battery was already in the high-temperature region from the very beginning of discharge, and the lower part was in the low-temperature region. The reason is that the irreversible heat was dominant at this time, and the heat producing rate of the upper area was higher due to the significant polarization phenomenon (difference of ion concentration) and high output current (electron transfer), most joule heat and polarization heat were concentrated in the upper part of the battery. In addition, it was found that the temperature-rise rate of the current collector was greater than the cell temperature in the condition of high discharge rates. A large amount of joule heat was generated when the higher current passes through the current collectors, and it was indicated that the heat conduction from the current collectors to the cell was one of the main factors that affect the distribution of the cell temperature. Due to a different direction of heat flux in the case of high and low discharge rates, the heat conduction of the current collectors needs to be considered in the thermal analysis.

\subsection{Temperature uniformity}

\subsubsection{Effect of Depth of Discharge (DOD)}

Fig. 6 shows the IR images at a discharge rate of 3C at DOD of $10 \%, 30 \%, 50 \%, 70 \%$ and $90 \%$ respectively, which are used to demonstrate variations of the visualized temperature distribution. The non-uniform of temperature distribution occurred and variation of the temperature became stronger during the discharge process as shown in Fig. 6. To assess the temperature variation and distribution quantitatively for laminated cells, $T_{\text {var }}^{2}$ was proposed to assess numerical deviation of temperatures. The larger $T_{\mathrm{var}}^{2}$ values, the greater temperature fluctuations and non-uniformity of the battery surface. 

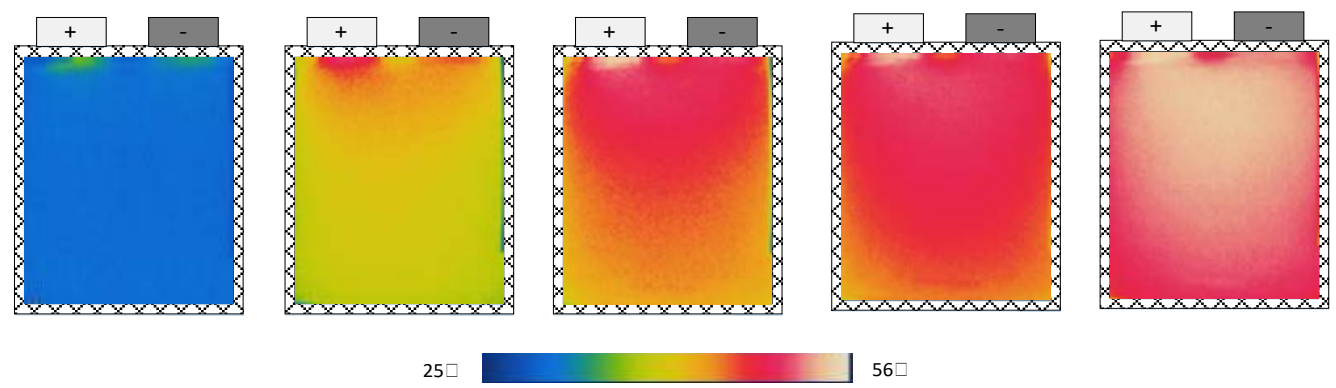

(a) $10 \% \mathrm{DOD}$

(b) $30 \%$ DOD

(c) $50 \% \mathrm{DOD}$

(d) $70 \%$ DOD

(e) $90 \% \mathrm{DOD}$

Fig. 6. Variation of temperature distribution at different DODs

Fig. 7 (a) shows $T_{\text {var }}^{2}$ with the variation of DOD at a constant discharge rate of 3 C. The $T_{\text {var }}^{2}$ presented a remarkable increase tendency with DOD rising from $10 \%$ to $40 \%$ due to the noticeable differences of heat generation rates between upper and lower areas. As shown in Fig. 7 (a), When DOD was among $40 \%$ and $80 \%, T_{\text {var }}^{2}$ was stabilized within 1.5 to 1.9 after sufficient thermal conduction since the degree of polarization became stable and temperature in each part of battery was getting close. At this stage, the NCM LIB reached the voltage platform, and the polarization degree tended to be stable. Nevertheless, at the final stage of the discharge process with DOD over $80 \%, T_{\text {var }}^{2}$ increased due to the significant increase in internal resistance. At the end of the discharge process, the internal resistance of battery increased rapidly leading to a wide gap of temperature rising rates in each part of the battery. As aforementioned, temperature values at the initial and final stages of high-power discharge deviated from the average rapidly and thus formed a temperature gradient.

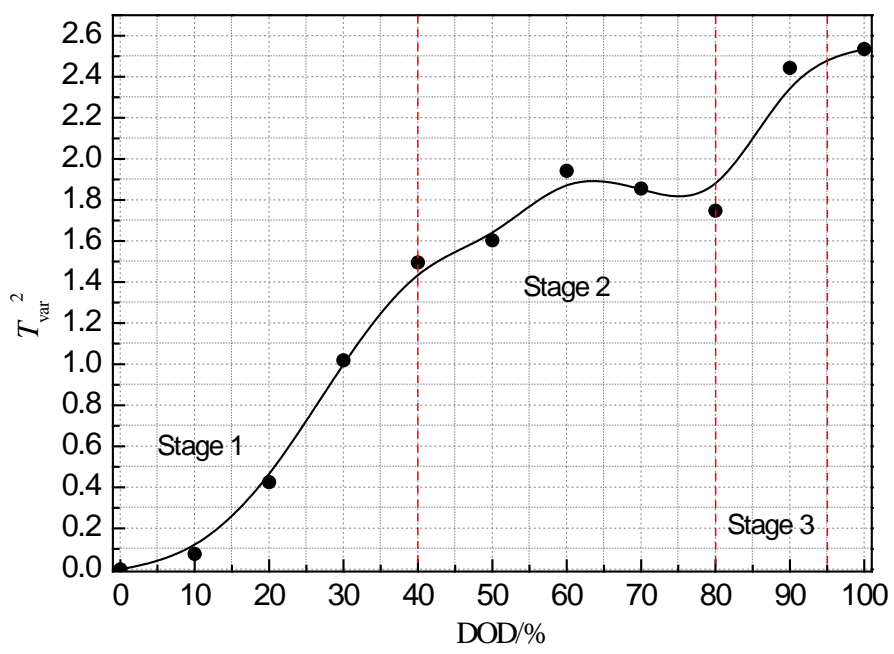

(a) $T_{\text {var }}^{2}$ at $3 \mathrm{C}$ 


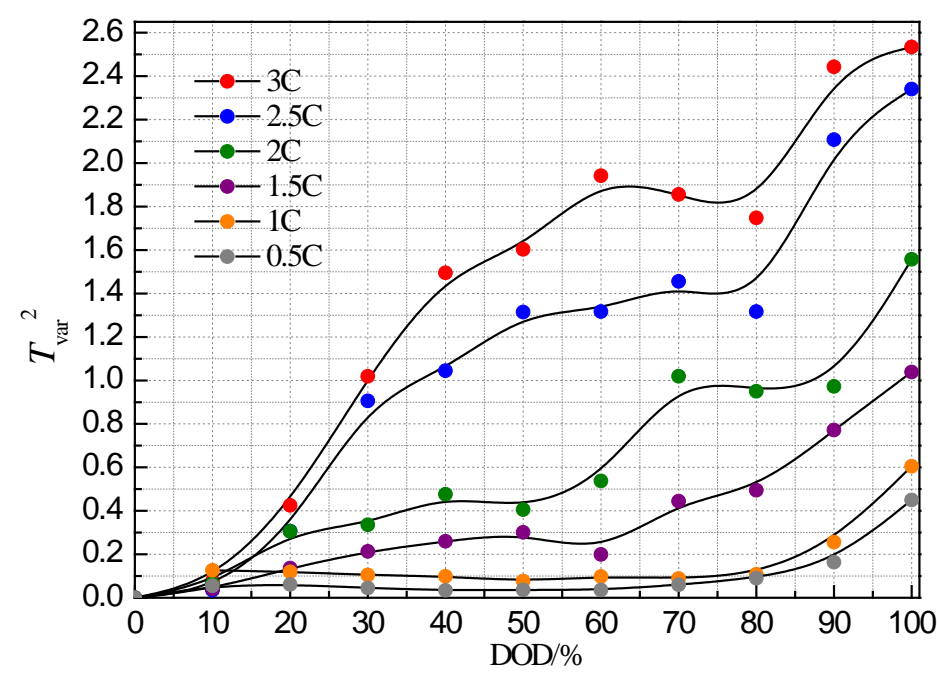

(b) $T_{\text {var }}^{2}$ at $0.5 \mathrm{C}-3 \mathrm{C}$

Fig. 7. $T_{\text {var }}^{2}$ vs. DOD at different discharge rates

\subsubsection{Effect of discharge rates}

Fig. 7 (b) illustrates $T_{\text {var }}^{2}$ at different discharge rates from $0.5 \mathrm{C}$ to $3 \mathrm{C}$. $T_{\text {var }}^{2}$ shows a considerable increase tendency with increasing discharge rates due to different heat producing rates. When the discharge rate was low with a relatively low current and long discharge time, the surface temperature of the battery shown better uniformity after a sufficient heat conduction, especially when the discharge rate was lower than $1 \mathrm{C}$. For a high discharge rate, the irreversible heat was dominant and the polarization increased significantly, therefore the heat producing rate was higher with a more concentrated area of heat production, and the discharge time was also shorter with concentrated heat which cannot be dissipated within a short time - leading to a larger temperature gradient. At the same time, in the discharge process, temperature uniformity showed a regular change. When discharge rates and DOD increases, the temperature fluctuations showed an increasingly non-uniform trend, especially at the end of the discharge. As the discharge process of the battery was an unsteady heat transfer process, both the process time of heat transfer and the heat producing rate of internal heat source have significant effects on the battery temperature distribution.

\subsection{Local overheating}

Previous research has shown that the thermal runaway of a battery was always caused by localized overheating rather than overall heat. In the current study, the temperature distribution of the battery surface was studied. Besides the numerical fluctuation, the spatial distribution of the high-temperature points was also investigated. MATLAB programming 
was used for temperature data analysis and to quantify high-temperature points distribution, with the operation procedure shown in Fig. 2. Fig. 8 (a) (b) visually shows the localized overheating index ( $\mathrm{LOH})$. Fig. 8 (a) indicates that $\mathrm{LOH}$ was high when high-temperature points were decentralized and scattered, while Fig. 8 (b) shows that LOH was low when hightemperature points were concentrated.

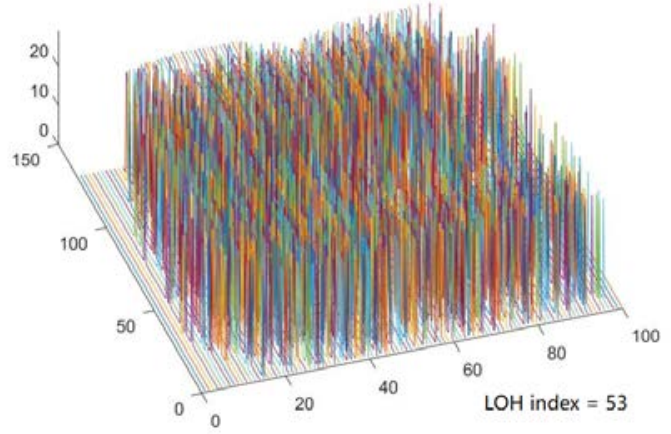

(a) LOH in a decentralized case

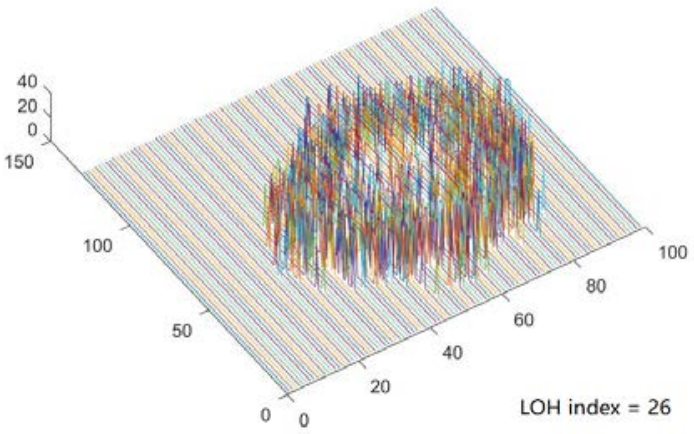

(b) $\mathrm{LOH}$ in a centralized case

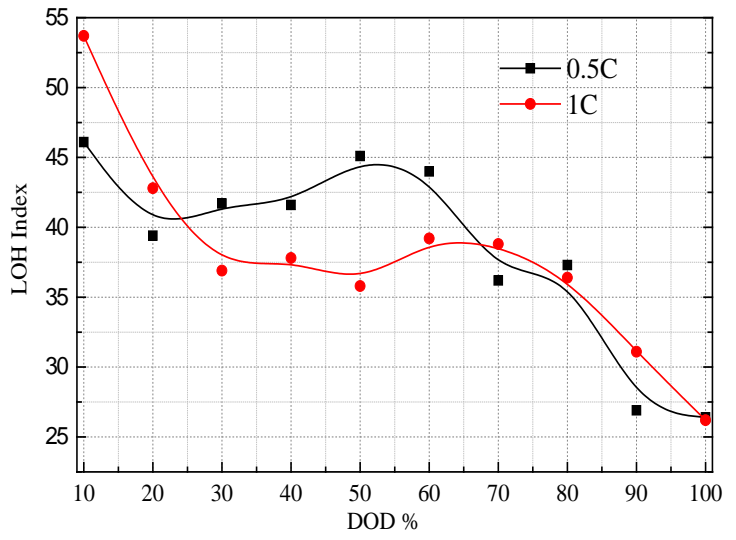

(c) $\mathrm{LOH}$ at low discharge rates

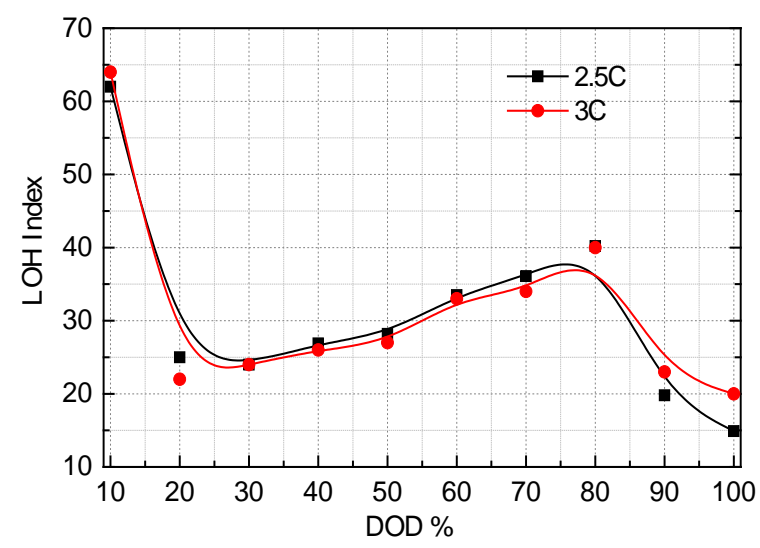

(d) $\mathrm{LOH}$ at high discharge rates

Fig. 8. Visualized LOH index at different discharge rates.

As shown in Fig. 8 (c), the high-temperature points of the battery surface were uniformly 
distributed (decentralized) at early stages of the discharge process for both $1 \mathrm{C}$ and $0.5 \mathrm{C}$. The high-temperature points were gathered and centralized gradually when increasing the discharge rate. In addition, the high-temperature area becomes relatively concentrated in the battery centre at the end of the discharge process. In general, in the case of low rate discharge, the $\mathrm{LOH}$ index decreased with the increase of the DOD, indicating that heat was gradually accumulated.

As shown in Fig. 8 (d), for high discharge rates of $2.5 \mathrm{C}$ and $3 \mathrm{C}$, initial temperature of the battery surface was uniform. With the increase of the DOD, high-temperature points were gathered rapidly and formed a very concentrated high-temperature area underneath of the current collectors; subsequently, the high-temperature area moved downward and hightemperature points spread out gradually. Since then, the high-temperature zone has rapidly gathered again at the end of discharge (over 80\% DOD). The local overheating phenomenon arose, and the degree of high-temperature concentration was similar to that of the initial discharge stage at 20\% DOD.

Similar to $T_{\text {var }}^{2}$, at the initial (0-30\% DOD) and final stage (80-100\% DOD) of high-power discharge, $\mathrm{LOH}$ index has a fast-changing trend indicating a rapid heat accumulation and concentration phenomenon which may cause thermal runaway of the battery. Due to such unique thermal characteristics, a higher requirement was putting forward to battery thermal management system.

To sum up, in the beginning and the end of discharge, the high-temperature area was relatively concentrated, so when designing a battery thermal management system, the local overheating phenomenon during the discharge process should be taken into account. To maintain temperature constancy and avoid local overheating phenomenon, local strengthened heat transfer or cooling means should be adopted so that the maximum temperature difference of the battery can be controlled within a reasonable range.

In the meantime, the current research also provides a certain reference for the battery cold start and design of the heating system. The cold battery discharge process is also a self-heating process, during which the phenomenon of temperature distribution appears. In the high-temperature area, a large temperature difference is caused due to self-heating effect. Therefore, in the design of a battery thermal management system, temperature distribution of the battery in the low-temperature area should be considered. For instance, according to the thermal characteristics of the battery, the low-temperature area should be given higher heating 
power by heating device. It is worth mentioning that the self-heating effect in the hightemperature area should be utilized to achieve a more uniform temperature distribution, with a reduction of energy consumption and an improved electrical performance.

\section{Conclusion}

Thermal safety issues have been the main obstacle to restrict the application of lithium-ion batteries in large size and high energy density development. However, few studies have considered the thermal characteristics within a single large cell, which should be the basic design reference for the thermal management system of battery packs. As batteries grow larger, internal temperature difference can no longer be neglected. In the current study, the thermal characteristics of an NCM LIB in the condition of natural convection were comprehensively assessed and experimentally investigated with the infrared imaging (IR) technology. Furthermore, two significant factors, i.e., the temperature variance $\left(T_{\mathrm{var}}^{2}\right)$ and local overheating index ( $\mathrm{LOH}$ index) were proposed to assess the temperature fluctuation and distribution of an NCM LIB under different discharge rates and DODs. The experimental results and analysis quantified the heat generation and distribution in space and time, revealed different thermal characteristics between high and low power discharge and provided a certain reference for the battery thermal management in local enhanced heat transfer cooling or uneven heating. These factors can be used in predicting heat accumulation and preventing the thermal runaway. The current study should have a positive influence on the future development of the battery thermal management system design.

The results showed that during the discharge process, the overall temperature distribution at low discharge rates was different from that at high rates due to different directions of heat flow between current collector and battery core. For a low discharge rate, the final hightemperature zone was stable in the center of the battery, while low-temperature zone appears in the upper area of battery. While at a high discharge rate, the highest temperature region was close to the positive electrode, and the lowest temperature region was far from the positive electrode. $T_{h}$ and $T_{l}$ area was $\{(x, y) \mid x \in-55.6 \sim-37.8, y \in 106.2 \sim 120.4\}$ and $\{(x, y)$ $\mid x \in 45.9 \sim 97.5, y \in-102.3 \sim-117.5\}$.

In the $\mathrm{X}$ direction, the temperature of the positive electrode side was higher than that in the negative side, because that in theory the positive current collector showed a higher heat generation rate than that of the negative one. In addition, under a high-power discharge, the temperature difference mainly appeared along the $Y$ direction. The temperature decreased gradually from the collector side to the lower part of the battery. The maximal surface 
temperature difference was approximately $12.2^{\circ} \mathrm{C}$ at $3 \mathrm{C}$, due to the heat generation rate being significantly higher on the collector side.

Finally, the temperature distribution showed an increasingly non-uniform trend in the aspects of both numerical fluctuation and spatial distribution with the increase of the discharge rate and DOD. Especially for high discharge rates, the high-temperature points deviated from mean temperature rapidly, and formed a very concentrated high-temperature area with the increase of the DOD. Both $\mathrm{LOH}$ index and $T_{\text {var }}^{2}$ have a fast-changing trend at the initial and final stage of high-power discharge, indicating the aggravation of the local overheating and a potential risk of thermal runaway.

\section{Acknowledgments}

The work is supported by De Montfort University through its distinguished Vice-Chancellor 2020 Programme, UK Science and Technology Facilities Council (STFC) through Batteries Early Career Researcher Award and the Ministry of Science and Technology of China through the Programme of International Cooperation (2016YFE0118600).

\section{References}

[1] Zhao J, Rao Z, Huo Y, Liu X, Li Y. Thermal management of cylindrical power battery module forextending the life of new energy electric vehicles. Appl. Therm. Eng. 2015;85:33-43.

[2] An Z, Ji L, Wei L, Dang C, Peng Q. Investigation on lithium-ion battery electrochemical and thermal characteristic based on electrochemical-thermal coupled model. Appl. Therm. Eng. 2018;137:792-807

[3] Chen D, Jiang J, Kim GH, Yang C, Pesaran A. Comparison of different cooling methods for lithium ion battery cells. Appl. Therm. Eng. 2016;94:846-854.

[4] Zhang J, Wu B, Li Z, Huang J. Simultaneous estimation of thermal parameters for largeformat laminated lithium-ion batteries. J. Power Sources 2014;259 (7):106-116.

[5] Giuliano MR, Advani SG, Prasad AK. Thermal analysis and management of lithiumtitanate batteries. J. Power Sources 2011;196(15):6517-6524.

[6] Onda K, Ohshima T, Nakayama M, Fukuda K, Araki T. Thermal behavior of small lithium-ion battery during rapid charge and discharge cycles. J. Power Sources 2006;158(1):535-542.

[7] Wang H, Tang A, Wang K. Thermal behavior investigation of $\mathrm{LiNi}_{1 / 3} \mathrm{Co}_{1 / 3} \mathrm{Mn}{ }_{1 / 3} \mathrm{O}_{2}$ based Li-ion battery under overcharged test. Chin. J. Chem. 2011;29(1):27-32.

[8] Zhao R, Gu J, Liu J. An investigation on the significance of reversible heat to the thermal 
behaviour of lithium ion battery through simulations. J. Power Sources 2014;266(1):422432.

[9] Xiao M, Choe SY. Theoretical and experimental analysis of heat generations of a pouch type $\mathrm{LiMn}_{2} \mathrm{O}_{4}$ /carbon high power Li-polymer battery. J. Power Sources 2013;241(11):46-55.

[10] Kim US, Shin CB, Kim CS. Modelling for the scale-up of a lithium-ion polymer battery. J. Power Sources 2009;189(1):841-846.

[11]Chacko S, Chung YM. Thermal modelling of Li-ion polymer battery for electric vehicle drive cycles. J. Power Sources 2012;213(9):296-303.

[12] Inui Y, Kobayashi Y, Watanabe Y, Watase Y, Kitamura Y. Simulation of temperature distribution in cylindrical and prismatic lithium ion secondary batteries. Energ. Convers. Manage. 2007;48 (7):2103-2109.

[13] Huria T, Ceraolo M, Gazzarri J, Jackey R. High fidelity electrical model with thermal dependence for characterization and simulation of high power lithium battery cells. Electric Vehicle Conference IEEE 2012;1-8.

[14] Yi J, Kim US, Shin CB, Han T, Park S. Three-dimensional thermal modelling of a lithium-ion battery considering the combined effects of the electrical and thermal contact resistances between current collecting tab and lead wire. J. Electrochem. Soc. 2013;160(3): A437-A443.

[15]Zhao L, Yu X. Wei L, Qiu L, Zhang L, Meng X, Jin L. Parametric study of forced air cooling strategy for lithium-ion battery pack with staggered arrangement. Appl. Therm. Eng. 2018;136:28-40.

[16] Guo M, White RE. A distributed thermal model for a Li-ion electrode plate pair. J. Power Sources 2013;221(1):334-344.

[17]Lee KJ, Smith K, Pesaran A, Kim GH. Three dimensional thermal-, electrical-, and electrochemical-coupled model for cylindrical wound large format lithium-ion batteries. J. Power Sources 2013;241(6):20-32.

[18] Mao J, Tiedemann W, Newman J. Simulation of temperature rise in Li-ion cells at very high currents. J. Power Sources 2014;271:444-454.

[19] Sun UK, Monroe CW, Christensen J, Albertus P, Cook D. Thermoelectrochemical simulations of performance and abuse in 50-Ah automotive cells. J. Power Sources 2014;268(3):625-633.

[20] Bin WU, Zhe LI, Zhang JB. Thermal design optimization of laminated lithium ion battery based on the analytical solution of planar temperature distribution. Scientia Sinica Technologica 2014;11:1154-1172.

[21] Li M, Wang F. Thermal Performance Analysis of the Lithium-Ion Batteries. International Conference on Parallel and Distributed Computing, Applications and Technologies IEEE, 
2011;483-486.

[22] Kim US, Shin CB, Kim CS. Effect of electrode configuration on the thermal behaviour of a lithium-polymer battery. J. Power Sources 2008;180(2):909-916.

[23] Dong HJ. Numerical modelling of lithium ion battery for predicting thermal behaviour in a cylindrical cell. Curr. Appl. Phys. 2014;14(2):196-205.

[24] Niculuţă MC, Veje C. Analysis of the thermal behavior of a $\mathrm{LiFePO}_{4}$ battery cell. J. Phys. Conf. 2012;39 (1):2013.

[25] Yang X, Lu Z, Bai Q, Zhang Q, Jin L, Yan J. Thermal performance of a shell-and-tube latent heat thermal energy storage unit: role of annular fins. Appl. Energ. 2017;202:558570.

[26] Yang X, Feng S, Zhang Q, Chai Y, Jin L, Lu T. The role of porous metal foam on the unidirectional solidification of saturating fluid for cold storage. Appl. Energ. 2017;194: 508-521.

[27] Xu J, Lan C, Qiao Y, Ma Y. Prevent thermal runaway of lithium-ion batteries with minichannel cooling. Appl. Therm. Eng. 2017;110:883-890.

[28] Iretomiwa E, Krishna S, Ankur J, Measurements and modeling to determine the critical temperature for preventing thermal runaway in Li-ion cells, Appl. Therm. Eng. 2018;145:,287-294, 